\title{
INAPPROPRIATE SEXUAL BEHAVIOURS EXPERIENCED BY SPEECH-LANGUAGE PATHOLOGISTS AND AUDIOLOGISTS IN SOUTH AFRICA
}

\author{
Karen Levin and Loren Traub
}

Speech Pathology and Audiology

University of the Witwatersrand

\begin{abstract}
The experience of inappropriate sexual behaviours (ISB) by healthcare professionals has been identified internationally as a serious issue. This study investigated the extent of ISB directed towards speech-language pathologists and/or audiologists (SLP/AS) in South Africa, as well as the sources and the effects of ISB, the responses of the SLP/AS, and the perceptions of the SLP/AS with regard to their ability to manage ISB experiences. Fifty-six qualified SLP/AS and 62 student SLP/As completed a questionnaire based on similar studies conducted in Canada and New Zealand. Most of the respondents had experienced ISB, mostly of a mild to moderate nature, at some point in their careers, and some had experienced severe ISB in the workplace. ISB occurred in a variety of work contexts. The sources of ISB included clients and/or their family members, as well as colleagues and employers. A range of personal and work-related effects resulted and the respondents took the least assertive strategy in the management of their ISB experiences. The results reflected that SLP/As in Suth Africa are poorly informed with regard to their legal rights and responsibilities, as well as strategies to deal with unwanted sexually related experiences. ISB ought to be recognised as a serious issue in clinical practice in South Africa by SLP/As, professional bodies as well as training institutions. The results are in line with previous research on ISB experiences by SLP/As and other healthcare professionals.
\end{abstract}

Key words: sexual harassment; speech pathology and audiology; professional-patient relationships

\section{INTRODUCTION}

Sexual harassment is a ubiquitous phenomenon that pervades all levels of society. Notwithstanding wide ranging debates on sexual harassment, the definition is broad and controversial because the experience is personal and individualised. The South African Labour Relations Act of 1995, section 203(2) of the Department of Labour (1995) defines sexual harassment as unwanted conduct of a sexual nature which is persistent (although a single incident of harassment can constitute scxual harassment). According to the Act, the behaviour can only be deemed as harassment if the recipient has made it clear that the behaviour is considered offensive. In addition, central to the Act is the condition that the perpetrator should have known that the behaviour is regarded as unacceptable. In contrast, the United States Equal Employment Opportunity Commission (1980) within the Civil Rights Act of 1964 (EEOC) recognises that the perpetrator may he completely unaware that his or her behaviour is offensive or constitutes sexual harassment or may be completely unaware that his or her actions could be unlawful, and furthermore, the EEOC recognises that it may not be possible for the recipient to express in any way that the behaviours are unwelcome.

As well as the difficulties inherent in formalised definitions of sexual harassment, blurring of boundaries occurs in personal experience and perceptions in that unwanted sexual behaviours are not always construed by the recipient as being of a harassing nature (Williams, de Seriere \& Bodington, 1999). In recognition of the alienating and judgemental implications of the term 'harassment', McComas, Herbert, Giacomin, Kaplan \& Dulberg (1993) used the term 'inappropriate patient sexual behaviours' in their investigation of the experience of inappropriate sexual behaviours (ISB) by physiotherapists in Canada. Their findings, as well as those of Williams et al. (1999) in New Zealand who identified the experience of ISB by speech-language pathologists, confirmed that rehabilitation therapists do not al- ways construe the experience of ISB as sexual harassment. The absence of a universal definition is evident in the vast literature that debates terminology and semantics in sexual harassment and also in international legal texts and depositions which lack consistency and agreement.

In the absence of a universal definition, models of sexual harassment can help to clarify the boundaries between what is acceptable and what is unacceptable, which helps to determine perceptions of harassment (McComas et al., 1993). One of the most commonly used models differentiates 'quid pro quo harassment' from 'hostile environment harassment'. Quid pro quo harassment involves a person in a superior position using sexual harassment as an expression of power to achieve his or her aims. In contrast, hostile environment harassment occurs when an equal peer engages in sexual behaviours that create a hostile environment. This differentiation is reflected in the definitions provided by the South African Labour Relations Act (Department of Labour, 1995), the EEOC (1980), as well as the Commonwealth Sexual Discrimination Act (1984) which constitutes federal law in Australia.

McComas et al. (1993) made use of a similar model in their study in Canada which examined the extent and nature of ISB directed at physiotherapists. They concluded that most ISB was directed by equal peers, or non-superiors, and thus fell into the category of hostile environment harassment. However, their respondents did not identify their experiences of ISB as harassment. The experience of both quid pro quo harassment as well as hostile environment harassment has been reported widely by healthcare professionals internationally, such as nurses (Henderson, 2003; Madison \& Minichiello, 2001; Tang, Yik, Cheung, Choi \& Au, 1996); physiotherapists (McComas et al., 1993; O'Sullivan \& Weerakoon, 1999); pharmacists (BroedelZaugg, Shaffer, Mawer \& Sullivan, 1999); and medical doctors (Recupero, Heru, Price, \& Alves, 2004; Vukovich, 1996). Researchers estimate that almost one in every two women experi- 
ence ISB at some point in their working lives (Fitzgerald, 1993; Gutek, 1985). A study conducted by the Institute of Directors in 1992 estimated that $76 \%$ of South African women experience ISB in the workplace (Vetten, 2001). Therefore the professions of speech pathology and audiology, which are predominantly female professions in South Africa, cannot ignore ISB as a professional issue because the experience of ISB poses a serious risk to both the emotional and physical well-being of a person (Schneider, Swann \& Fitzgerald, 1997). However, despite the feminisation of some professions such as speech pathology and audiology, Rothstein (1993), in his commentary on McComas et al.'s (1993) study, argued that ISB should be viewed as a professional issue, and cited Bruckner (1993) who argued that ISB is not primarily a women's issue.

The experience of ISB is a serious professional issue because of the extent of the harm that it can cause (McComas et al., 1993). Some theorists, particularly within the psychological as opposed to the legal paradigm, argue that the consequences, rather than the intentions, are the determining factors in the definition of harassment (Fitzgerald, 1993; Gutek \& Koss, 1993; Madison \& Minichiello, 2001). The consequences of the experience of ISB, whether the person defines the experience as harassment or not, include a range of negative effects in the workplace, such as decreased morale, increased absenteeism, decreased job satisfaction, job loss, and deteriorating relationships with coworkers (Schneider et al., 1997). Furthermore, the experience of ISB often has a serious effect on people's physical and emotional health and the more severe the ISB the more severe the reactions (Gutek \& Koss, 1993; Schneider et al., 1997). The reactions reported by both men and women who have been the recipients of ISB include anxiety, depression, sleep disturbance, weight loss or gain, loss of appetite, headaches, feelings of frustration, fear, anger, embarrassment, shock, alienation, and loss of self-esteem (McComas et al., 1993; Schneider et al., 1997). According to Schneider et al. (1997), ISB may lead to symptoms of posttraumatic stress disorder. They wrote that people who experience sexual harassment exhibit similar psychological effects as victims of trauma. Furthermore, people who have experienced ISB in the workplace are likely to experience it on an on-going basis rather than as an isolated incident.

Rothstein's (1993) view of ISB as a professional issue provided a lens through which the management of the experience of ISB may be viewed. The healthcare practitioner's experience of ISB results from multifaceted interactions of a complex array of factors including personal, environmental, and societal influences, underscored by their role as professionals. This role begins in education and a number of studies have shown that student health care professionals are at risk for experiencing high levels of ISB (McComas et al., 1993; Recupero et al., 2004; Vukovich, 1996; Williams et al., 1999). ISB that is experienced in the workplace of the healthcare professional may be influenced by the setting, the nature of the work, as well as the clients. The settings in which healthcare professionals' work place them at risk for the experience of ISB, are places such as consulting rooms, quiet audiology booths, and hospital wards. Close physical contact is necessary in many aspects of healthcare. Healthcare workers may provide -a sympathetic ear to clients and/or their caregivers and family members, and transference is a well-documented phenomenon in healthcare provision. Sexual control problems may be experienced by the clients served by healthcare professionals, such as patients with brain injury (Bezeau, Bogod \& Mateer, 2004; Lawrie \& Jillings, 2004; Philips \& Schneider, 1993), and severe learning disabilities (Murphy, 2003). Recently, models for effective management of ISB with people who have sexual behaviour control issues have been described in the literature (Bezeau et al., 2004; Lawrie \& Jillings, 2004).

ISB was identified as a serious professional issue in speech-language pathology by Williams et al. (1999) who investigated the experiences of ISB by members of the New Zealand Speech-Language Therapists' Association as well as third and fourth year students studying speech-language pathology. Williams et al. did not include audiologists in their study. More than two-thirds of the students and almost $85 \%$ of the qualified speechlanguage pathologists reported at least one experience of ISB. The current study was designed to determine the experiences of ISB directed to SLP/As in South Africa because variables that impinge on professional practice may differ in different geo-political contexts.

\section{METHODOLOGY}

Aims

The primary aim of this study was to investigate the extent and nature of the experience of ISB by qualified speech-language pathologists and audiologists (SLP/A) as well as students studying speech-language pathology and/or audiology in South Africa. The study aimed to determine (a) the extent of SLP/As experience with ISB; (b) the type of ISB encountered; (c) the sources of ISB in their workplace (d) SLP/As perceptions of the consequences of their ISB experiences, (e) the strategies employed by SLP/As to manage their ISB experiences, and (f) SLP/As perceptions with regard to their preparedness to deal with ISB in the professional setting.

\section{Research design}

This study took the form of a postal survey research design because the aim was to partially replicate the study conducted by Williams et al.(1999) in New Zealand who adapted a questionnaire developed by MComas et al. (1993). A survey design was appropriate for this study because it allowed the researchers to access a large sample. The anonymity assured by the design gave the respondents more opportunity to answer honestly questions which related to very personal information on a sensitive topic (Babbie, 1995). One of the disadvantages of survey research is that the answers may be unreliable as a result of misunderstanding of the question or the irrelevance of the question to the respondents. Furthermore, the researcher has little control over when and where the questionnaire is answered. The respondents may leave questions unanswered, not understand questions or not answer the questionnaire in privacy. However, the survey had been used successfully by McComas et al. (1993) as well as Williams et al. (1999).

\section{Ethical considerations}

The researchers were granted permission to conduct this research by the Ethics Committee (Humanities) of the University of the Witwatersrand. Because of the sensitive nature of some of the questions that could evoke difficulties for the respondents, a list of available counselling services was attached to the questionnaire. Included in the information letter that was attached to each questionnaire was an assurance of confidentiality and anonymity of the participants. The participants were informed that participation in this study was voluntary and that their completion of the 
questionnaire was interpreted as their consent to participate in the study. They were asked to avoid including any identifying information in the questionnaire, and were asked to mail the responses in a sealed envelope directly to the researchers.

\section{Participants}

\section{Participant Selection Criteria}

Participants were required to be SLP/As working in South Africa or SLP/A students at South African universities. The students were required to be in their third or fourth year of study because they would have had contact with clinical work by this level of study.

\section{Sampling}

Qualified SLP/As. A mailing list of all registered SLP/As was obtained through the South African Speech Language and Hearing Association (SASLHA). Systematic sampling was used to gain a representative sample from the larger population. This requires less time, and is cheaper and more practical than simple random sampling. However, it is not as accurate as simple random sampling and it may result in a cyclical order of sampling, which may result in a biased sample (Babbie, 1995). Although this method of sampling results in a sample of convenience, the researchers were intent on surveying SLP/As nationally. The questionnaire was mailed to 78 qualified SLP/As.

Student SLP/As. The questionnaire was distributed to 262 students in the third and fourth year of study at all South African universities that train SLP/As.

\section{Response rate}

Qualified SLP/As. According to Babbie (1995), a 50\% response rate for postal surveys allows for adequate analysis and provides an accurate representation of the subjects. Fifty-six questionnaires were returned by qualified SLP/As, which yielded a response rate of $71.7 \%$. This high response rate implies that the respondents had an interest in this topic and alludes to the importance of the experience of ISB in clinical practice in South Africa. All of the responses received were from female SLP/As. It is possible that no male SLP/As received a questionnaire as a result of the sampling procedure which did not take into account the few male SLP/As in South Africa. The lack of information with regard to the experiences of male SLP/As in South Africa is an important limitation of this study, given the number of studies that have demonstrated that male health care workers experience ISB (Broedel-Zaugg et al., 1999; Madison \& Minichiello, 2001; McComas et al., 1993).

Student SLP/As. Sixty-two questionnaires were returned by student SLP/As which yields a response rate of $23.6 \%$. All the universities that were included in the survey were represented in the sample. The low return rate renders the data unrepresentative of the student population and therefore leads to difficulties in the interpretation of the results. It is possible that the students had not been exposed to any of the behaviours targeted in this study. Alternatively, perhaps the poor response rate was due to the fact that the survey was conducted at a particular time of year in the university timetable which included examinations followed by a vacation period. The researchers acknowledge that this poor return rate is a limitation of the study, and that the generalisability of the results to the general student population is restricted. As with the qualified SLP/As all the respondents were female and thus the results can only be generalised to the female population of student SLP/As.

\section{Description of participants}

Fifty-six qualified SLP/As and 62 student SLP/As participated in the study. The demographic data of the qualified SLP/As are summarised in Table 1. The qualified SLP/As ranged in age from 20-65 years, and in experience from new graduates to clinicians with more than 20 years experience. The participants worked in a variety of settings. The sampling method might have been inappropriate to some extent in that work contexts were not necessarily represented fairly. For example, only one respondent worked in a university setting. Fifty-seven of the student SLP/As ranged in age from 20-24 years and five were between 26 and 30 years of age. Sixteen students were in third year and 46 students were in fourth year.

\section{Table 1: Demographic Data of Qualified SLP/As}

\begin{tabular}{|c|c|}
\hline Age in years & $\mathbf{N}$ \\
\hline $20-25$ & 5 \\
\hline $26-30$ & 27 \\
\hline $31-50$ & 19 \\
\hline $50+$ & 5 \\
\hline Years in practice & $\mathbf{N}$ \\
\hline $0-5$ & 18 \\
\hline $6-10$ & 12 \\
\hline $11-20$ & 11 \\
\hline $20+$ & 15 \\
\hline Place of work & $\mathbf{N}$ \\
\hline University & 5 \\
\hline School & 18 \\
\hline Hospital & 16 \\
\hline Private Practice & 20 \\
\hline Rehabilitation unit & 5 \\
\hline
\end{tabular}

\section{Procedure}

\section{Questionnaire Design}

Williams et al. (1999) adapted a questionnaire developed by McComas et al. (1993) who investigated ISB directed at physiotherapists in Canada. Neither McComas et al. nor Williams et al. published their questionnaires, and thus the present researchers developed a questionnaire based on the reports of Williams et al. and McComas et al. Workplace settings were defined as they exist in South Africa as well as to accommodate audiologists who were not surveyed by Williams et al. Additionally, the participants were asked to indicate whether they perceived the behaviour to be symptomatic of the client's condition. Hence, the current study was a partial replication of Williams et al. The researchers acknowledge the limitations implied by a lack of piloting the questionnaire which was the result of time pressure to complete the study.

Although the researchers were aware that English is not the home language of all SLP/As in the country, the questionnaire was produced in English only and home language was not a consideration in the participant selection criteria. The reasons for this limitation were the time and financial constraints imposed by the study. However, most of the professional literature that is consulted by SLP/As is in English, and therefore SLP/As are presumed to have a fairly good reading comprehension level of English. Of note is that five completed questionnaires had comments written in Afrikaans in the open-ended sections. The researchers 
acknowledge that the language of the questionnaire might have limited the number and/or quality of the responses.

The information letter that was attached to the questionnaire emphasised that the questionnaire pertained to the experience of ISB in the workplace only. The questionnaire was presented with the topic of the research as 'The Experience of Inappropriate Sexual Behaviour in the Workplace', which served to remind the respondents that the survey was focussed on the workplace.

The questionnaire consisted of a total of five sections, which included both open and closed type questions. Nonexhaustive categories were added to ensure that all possible responses were catered for (Babbie, 1995). This took the form of "other" and "add any comments".

The first section consisted of a set of questions to determine the biographical data of the respondents. The information that was sought included gender, age, years of experience or year of study (for students) and place of work. No information was sought with regard to variables such as home language, cultural background, gender identity, race, or ethnicity because of the scope of the study. However, this information might have contributed to the depth of the analyses and the information that was obtained. The second section consisted of a set of questions to determine the types of ISB experienced by the participants. These took the form of yes/no questions. This section was based on the questions published by Williams et al. (1999), which described and classified ISB as mild, moderate, or severe. The third section consisted of a set of questions to determine from whom the ISB was experienced as well as in which contexts it was experienced. The fourth section consisted of a set of open-ended questions to determine the effects on the participants as a result of the experience of ISB. The final section consisted of a set of closed-ended and open-ended questions to determine the various ways in which ISB was managed and what the respondents felt about training at an undergraduate level. One closed-ended question asked respondents whether they had knowledge about the law in South Africa regarding ISB. Respondents were invited to add any extra comments. (See appendix for copy of the questionnaire).

\section{Distribution of Questionnaire}

Qualified SLP/As. Most of the questionnaires were sent by mail. Twenty questionnaires were hand delivered to the participants to reduce the postage costs. To ensure the participants' confidentiality, the completed questionnaires were not personally collected by the researchers but were returned by mail. All questionnaires included a stamped, addressed return envelope.

Student SLP/As. Questionnaires, along with the covering letters, were distributed to the SLP/A students at the University of the Witwatersrand in their private mailing boxes at the university by the researchers. The students were asked in the information letter that was attached to the questionnaire to place their sealed and completed questionnaires in a box allocated for this purpose. To ensure anonymity, they were asked to place the completed questionnaire in the envelope with which they had been provided and to seal it. For the students at the other universities, each head of department was mailed a batch of questionnaires, with a letter requesting that the questionnaires be distributed to all third and fourth year students. The information letter to all students requested that the questionnaires should be mailed directly to the researchers in the stamped return envelope which was attached to the questionnaire.

\section{Analysis of Data}

The questionnaire was analysed using descriptive statistics to summarise, organise and describe the data. Frequency counts were completed for each section of the questionnaire, resulting in descriptive data that accounted for the frequency of occurrence of ISB, the effects of the ISB, the contexts in which ISB was experienced as well as the management strategies that were employed. A broad thematic analysis was completed on the open-ended responses in line with the aims of the study and the themes that were identified, as well as personal stories, were analysed to complement the quantitative data (Pidgeon \& Henwood, 1996). McComas et al. (1993) categorised the severity of ISB which resulted in their division of the questions that they posed to their respondents into mild, moderate and severe categories. Because the questions that were employed in the current study were almost identical to those used by McComas et al., severity of the ISB was analysed as per their categories. The results of the qualified SLP/As and student SLP/As were analysed separately because of their possible differences with regard to age as well as clinical experience.

\section{Reliability and validity}

In order to control for the threat of researcher bias and to enhance the reliability of the analyses, a second rater was employed to analyse the responses (Babbie, 1995). The rater, a qualified SLP/A, was familiar with the research topic, as well as the Williams et al. (1999) study. The rater was given access to the raw data first and subsequently read the researchers' analyses of the data. Most of the data was analysed quantitatively and was therefore indisputable. However the qualitative data, generated by the open-ended questions and comments that were made by the respondents, were open to interpreter bias (Babbie, 1995). Furthermore, the qualitative data were used to support the interpretation of the quantitative data. In order to control for researcher bias the rater and the researchers discussed how best to represent the results and write up the findings (Pidgeon \& Henwood, 1996).

\section{RESULTS}

The results are presented in five sections as per the aims of the study.

\section{Severity and frequency of the experience of ISB}

The experiences of ISB were categorised as mild, moderate or severe as per McComas et al. (1993). The data revealed that $55 \%$ of the qualified SLP/As and $45 \%$ of the student SLP/As had experienced ISB at least once in their professional lives. The types and severity of ISB experiences are reflected in Table 2.

Mild ISB was experienced by $55 \%$ of the qualified SLP/As and $42 \%$ of the student SLP/As. Williams et al. (1999) reported that mild ISBs were underreported because the SLPs did not consider mild behaviours to be offensive. It is possible that underreporting occurred in the present study. Moderate ISB was experienced by $41 \%$ of the qualified SLP/As and $16 \%$ of the student SLP/As. Severe ISB was reported by $26 \%$ of the qualified SLP/As and $8 \%$ of the student SLP/As.

The classification of severity is an arbitrary one and in a way minimises the experiences in the mild category and draws attention to those in the severe category. The questionnaire did not ask the respondents to rate the severity; perhaps this is a limitation of the categorisation strategy employed by McComas et al. 
Table 2: Respondents' Reports of ISB Experiences (in \%)

\begin{tabular}{|c|c|c|}
\hline Question & Qualified & Student \\
\hline $\begin{array}{l}\text { Mild ISB } \\
\text { Have suggestive stories ever been told to you? } \\
\text { Has an offensive joke ever been told to you? } \\
\text { Have flattering remarks about your appearance that made you uncomfortable ever been made? } \\
\text { Have you been stared at in a way that made you uncomfortable? } \\
\text { Have you ever been asked for a date? } \\
\text { Has anyone suggested that you 'get together' for a drink? } \\
\text { Moderate ISB } \\
\text { Have crude sexual remarks been made to you? } \\
\text { Have any attempts been made to draw you into a discussion about your private sexual matters? } \\
\text { Have you ever been propositioned (e.g. asked you to have sex with him or her)? } \\
\text { Have you ever been deliberately touched (laid a hand on your bare arm or put an arm around your shoul- } \\
\text { ders) in a way that made you feel uncomfortable? } \\
\text { Severe ISB } \\
\text { Have you had genitals exposed to you? } \\
\text { Have you had breasts exposed to you? } \\
\text { Has anyone ever attempted to fondle you (stroked your leg or neck, touched your breasts)? } \\
\text { Has anyone ever made forceful attempts to touch you? } \\
\text { Has anyone ever made forceful attempts to fondle you? } \\
\text { Has anyone ever made forceful attempts to kiss you? } \\
\text { Has anyone ever made forceful attempts to grab you? } \\
\text { Has anyone ever made attempts to have sexual intercourse with you? } \\
\text { Has anyone ever used force to have intercourse with you? }\end{array}$ & $\begin{array}{c}5.3 \\
0 \\
5.3 \\
1.7 \\
1.7 \\
3.5 \\
3.5 \\
3.5 \\
1.7\end{array}$ & $\begin{array}{c}12.9 \\
29 \\
32.2 \\
17.7 \\
6.6 \\
0 \\
\\
\\
3.2 \\
6.4 \\
0 \\
11.2\end{array}$ \\
\hline
\end{tabular}

\section{The effects of ISB}

The respondents experienced a variety of physical and emotional reactions to their experiences of ISB as well as consequences in the work-setting. Most of the consequences that were reported were psychological, although the respondents experienced physical symptoms as well. Some of the consequences that were reported to have affected work performance were serious, such as the resignation of four SLP/As from their jobs. The study did not determine whether the effects were long-lasting or not. The frequency and nature of these effects are presented in Table 3.

\section{Sources of ISB}

The findings showed that $35 \%$ of the qualified SLP/As and $30 \%$ of the student SLP/As reported that ISB was predominantly directed by clients, and of these respondents, $28 \%$ of the qualified SLP/ As and $30 \%$ of the student SLP/As perceived that the perpetrators might be expected to have sexual control difficulties due to their underlying pathology. Other sources of ISB included the parents, spouses, and children of the clients. Patient's caregivers were reported to be the perpetrators of ISB by $4.8 \%$ of the student SLP/As. ISB was reported to have been perpetrated by employers and colleagues in senior positions by $8.9 \%$ of the qualified SLP/As, and $5.3 \%$ of the qualified SLP/As had experiences of severe ISB directed at them by hospital porters. None of the student SLP/As reported having experienced ISB from faculty workers or supervisors.
Table 3: Respondents Reported Effects of the Experience of ISB

\begin{tabular}{|c|c|c|}
\hline Effects of ISB & $\begin{array}{c}\text { Qualified } \\
\text { SLP/As }\end{array}$ & $\begin{array}{c}\text { Student } \\
\text { SLP/As }\end{array}$ \\
\hline Work Performance & 8.9 & 12.9 \\
Distraction & 5.4 & 3 \\
Decreased motivation & 7.1 & \\
Resignation & & \\
Physical Stress & 7.1 & 1 \\
Insomnia & 3.6 & 1 \\
Fatigue & & \\
Emotional Stress & 17.9 & 17.7 \\
Nervousness & 7.1 & 1.6 \\
Doubt & 10.7 & 3.2 \\
Guilt & 0 & 14.5 \\
Embarrassment & 10.7 & 3.2 \\
Self consciousness & 8.9 & 19.4 \\
Avoidance & 1.7 & 1.6 \\
Loss of confidence & 14.3 & 22.6 \\
Feeling uncomfortable & 7.1 & 3.2 \\
Feeling anxious & & \\
\hline
\end{tabular}




\section{Work settings in which ISB was experienced}

ISB was experienced by the respondents in a variety of work settings. ISB was experienced by $0.8 \%$ of the student SLP/ As and $20 \%$ of the qualified SLP/As in hospital settings. Similarly, ISB was experienced by $3.2 \%$ of the qualified SLP/As and $3.6 \%$ of the student SLP/As in rehabilitation centres. ISB was experienced in nursing homes by $4.8 \%$ of the qualified SLP/As and $5.3 \%$ of the student SLP/As.

ISB experience was reported in school settings by $8.1 \%$ of the qualified SLP/As and $1.7 \%$ of the student SLP/A, all of whom experienced ISB from their colleagues. Unfortunately, the questionnaire did not determine whether the perpetrators were superiors in the work-setting, although two of the respondents who described their experiences in the open section of the questionnaire reported that their ISB experiences were directed by their school principals.

ISB was experienced in private practice by $16.1 \%$ of the qualified SLP/As and by $1.6 \%$ of the qualified SLP/As in the industrial audiology setting, and was experienced in speechlanguage and/or hearing clinics attached to universities by $40 \%$ of the qualified SLP/As and $17 \%$ of the student SLP/As. ISB was experienced in rural settings by $4.8 \%$ of the student SLP/As.

\section{The management of ISB}

\section{Methods of dealing with ISB}

The experience of ISB was ignored by $30.3 \%$ of the qualified SLP/s and $38.7 \%$ of the student SLP/As. One of the strategies that were employed by $19.6 \%$ of the qualified SLP/As was to discuss the ISB with their clients, and $14.2 \%$ discussed the experience of ISB with their supervisors. Similarly, $11.2 \%$ of the student SLP/As chose to talk to their clinical tutors about the ISB, and $6.4 \%$ of the student SLP/As spoke to the clients. Calling on co-professionals to manage ISB within the team of healthcare professionals was employed by $3.6 \%$ of the qualified SLP/ As. Termination of intervention with a client as a result of ISB was reported by $1.7 \%$ of the qualified SLP/As. These findings are similar to those of Williams et al. (1999).

\section{Perceptions with regard to preparedness to deal with ISB in the professional setting}

Although $37 \%$ of the qualified SLP/As and $37 \%$ of the student SLP/As felt that they had handled the situation effectively, $82 \%$ of the qualified SLP/As and $58 \%$ of the student SLP/ As believed that specific training in the management of ISB would be beneficial. Moreover, $64 \%$ of the qualified SLP/As and $34 \%$ of the student SLP/As indicated that they had not received any training at any point in their careers with reference to the management of ISB in clinical practice. This finding was also evident in Williams et al. (1999) and McComas et al. (1993), who found similar trends with regard to SLPs and physiotherapists.

The respondents identified specific topics that they felt would be beneficial to include in a training programme. Qualified SLP/As and student SLP/As suggested similar topics such as assertiveness training, how to define ISB, deal with ISB, respond effectively to ISB, as well as procedures to report ISB. In addition, $85 \%$ of the qualified SLP/As and $58 \%$ of the student SLP/ As indicated that they were not familiar with the South African laws pertaining to ISB, and suggested that this aspect be included in training courses.

\section{DISCUSSION}

The results of this study showed that SLP/As in South Africa are vulnerable to the experience of ISB in their work settings. The high response rate, as well as the results of the study, confirms that the experience of ISB in the workplace is a serious professional issue. At least half of the respondents reported having experienced ISB at least once, and although the majority of these experiences were mild, many of the respondents had had to deal with the experience of severe ISB. The findings are similar to those established by Williams et al. (1999) although qualified SLP/As in South Africa reported more experiences with severe ISB. McComas et al. (1993) reported that half of their qualified physiotherapy respondents and a third of their students had experienced severe ISB. Despite the difficulties with explaining why the experience of severe ISB by the respondents was common, the results of the current study reveal that SLP/As in South Africa are vulnerable to severe personal harm, the most serious of which comprised violent encounters with co-workers, but also extended to experiences of ISB that the respondents did not know how to resolve and which led to remarkable life changes such as changing career direction and interest.

The value of examining the experience of ISB as a professional issue is warranted by the finding that the majority of ISB was directed by clients, their caregivers, or family members. Many theorists have attempted to provide a classification or a typology of the person who directs ISB. For example, Madison \& Minichiello (2001) described harassers in terms such as 'the confidante', 'one-of-the-gang', and 'the bully' among many others, which describe the wide variety of behaviours as well as intentions that characterise harassers. However, clients and their caregivers cannot be viewed as members of the typical workplace and therefore the typology of harassers does not necessarily translate into healthcare settings; indeed, the healthcare context is not necessarily comparable to commercial work environments, nor is there a set of features that defines healthcare contexts. However, clients who present with communication disorders and/or their caregivers can be viewed, in many cases, as vulnerable and fragile members within the healthcare context. While transference is a well recognised notion in the psychology of healthcare (Hall, 2001) the behaviours that result from transference and countertransference have not traditionally been labelled as harassment although they fit the definitions of harassment provided by the South African Labour Relations Act (Department of Labour, $1995)$ as well as that of the EEOC (1980). In most cases, the experience of ISB by the client is blamed on the healthcare professional's breach of the fiduciary relationship (Hall, 200i). Similarly, the person with a communication disorder who finds the SLP to be empathic and sensitive to his or her emotional needs might not be cognisant of the need, or have the skills, to maintain and limit their relationship boundaries such as role, space, language or physical contact (Hall, 2001). In a similar vein, it is well recognised that people who have sustained head injuries have problems with inhibition and the control over their sexual behaviours (Bezeau, et al., 2004). In line with this, ISB was identified as a symptom of the client's condition by most of the respondents in the current study. The South African Act (Department of Labour, 1995) specifies that the perpetrator is aware of his or her behaviour and knows that it could be unacceptable, but there is ample evidence that clients who have sustained head injuries have impaired executive function and reduced awareness and are thus not able to judge the appropriacy of their behaviours (Lawrie and Jillings, 2004). It is unfortunate that the questionnaire did not de- 
termine the type and severity of the disorders with which the clients presented.

The majority of respondents in the current study did not perceive the behaviours of clients and/or their caregivers as unacceptable or as harassing, although at least $10 \%$ of respondents classified their client's behaviours as harassment. This finding mirrors those of McComas et al. (1993) and Williams et al. (1999). Williams et al. posited that to label ISB as harassment implies that the healthcare professional has to apportion blame on the perpetrator, but victims of harassment prefer to apportion blame to themselves or to circumstances.

In the present study, the consequences did not necessarily determine whether the respondents perceived ISB to be harassment. One of the respondents resigned from her job because she could not cope with ISB directed by clients in a nursing home, but she did not perceive the ISB to be harassment. Rothstein (1993) suggested that healthcare professionals might be desensitised to the brutality of sexual harassment by the extent of violence and related sexual behaviours which are prevalent in modern society, and that the abuse might begin in student years. He wrote, "Perhaps shock gives way to coping in a perversion of the right of passage into professionalism" (p. 739). Rothstein did not take into account the nature of people who elect to enter the profession of SLP/A, nor the behaviours that are taught to SLP/As as they develop into clinicians. Although the literature is very sparse in the field of education of SLP/As, there is some evidence that suggests that SLP/As are taught to be accepting, unconditional, and empathic (Goldberg, 1997) but these attributes, if not moderated, could result in SLP/As being susceptible to abuse. Further research may help to explain why SLP/As did not view ISB directed by clients to be harassment even if the consequences were severe.

Not unlike the participants in the study conducted by Williams et al. (1999), respondents in the current study reported the experience of ISB directed by co-workers and colleagues. Williams et al. reported that more severe ISB was directed by clients but the current study did not concur. The most serious report in the current study was a violent encounter of a qualified SLP/A with a hospital porter who hurt the; respondent physically although actual sexual penetration did not occur.

None of the student SLP/Ass reported having experienced ISB fróm faculty workers or supervisors which was somewhat unexpected, given the figures that have demonstrated that ISB in educational settings remains a significant problem on campuses across the globe (Recupero et al,, 2004). It is possible that the poor response rate of the student SLP/As had an effect on the results. On the other hand, it is possible that in a predominantly female profession taught predominantly by women, that the chances of ISB are greatly reduced.

In contrast, ISB was experienced by the respondents in this study in most work settings. Kamel and Hajjar (2004) described the intense burden for nursing home staff created by ISB, which was true for the SLP/As in the current study. The hospital environment is a significantly risky environment as demonstrated by the results of the current study which is supported by the large body of research on ISB that is experienced by healthcare professionals in hospital settings (Phillips and Schneider, 1993; Recupero et al., 2004). In private practice, SLP/As may work alone or with a limited number of other SLP/As which leaves them relatively powerless and an easy target for an ISB experience. Additionally, SLP/As may meet with a client's parent or caregiver in the early mornings or evening, times which once again provide an opportunity for ISB to take place.|SLP/As also work often behind closed doors, a situation that creates vulnerability for them. The experience of ISB in rural settings is an important finding when considering the fairly recently introduced period of Community Service for newly qualified South African SLP/As, many of whom are placed in rural settings. In the main, new graduates are young, inexperienced in the work place, are in the earliest stages of independence and their dissociation from their clinical supervisors in the university setting. These variables place the new graduate at risk for ISB. Finally, the silence and isolation of audiology test environments places audiologists at risk for ISB.

Most of the respondents adopted the least assertive strategies to manage the experience of ISB, which was similar to the findings of Williams et al. (1999) and by researchers in allied healthcare professions (Schneider et al., 1997). For example, Sandberg, McNiel and Binder (2002) found that although nurses experience very high levels of quid pro quo sexual and hostile environment harassment, very few cases had been reported by the nurses that they studied. McComas et al. (1993) discussed research that has indicated that healthcare practitioners may not be prepared for the experience of ISB which then contributes to its reoccurrence. Ferns (2006) related her findings with regard to the actions taken by nurses to manage ISB to their gender, their exposure to violence in society, the status of their profession, as well as beaurocratic structures. The SLP/As in the current study chose to ignore ISB much of the time, but also chose to confront their clients and/or caregivers, or their colleagues. In line with the findings by Williams et al. (1999), most of the respondents perceived their actions to have been successful although most of them indicated that in-service training as well as training at the undergraduate levels would be beneficial. Students reacted in similar ways to qualified SLP/As although they reported that they avoided confrontation with the perpetrator of the ISB.

The experience of ISB is a serious issue, and yet not one respondent was aware of the laws in South Africa pertaining to sexual harassment. South Africa is one of few countries to prohibit sexual harassment directly through legislation. The Labour Relations Act of 1995, section 203 (1) includes the 'Code Of Good Practice On The Handling Of Sexual Harassment Cases' (Department of Labour, 1995). It is incumbent on SLP/As who are employers, managers, or employees, to be cognizant of the requirements of the Act. For example, the Act specifies that managers are responsible for ensuring that the workplace is free of sexual discrimination; that policy statements on sexual harassment should be communicated effectively to all employees; that employers should develop clear procedures to deal with sexual harassment; and that employers and employer organisations should include the issue of sexual harassment in their orientation, education and training programmes of employees.

\section{CONCLUSION}

This study of South African SLP/As revealed that more than half of the respondents had some degree of experience with ISB directed by their clients or their caregivers, and colleagues in their professional lives. Most experiences were mild to moderate, although severe experiences were reported, and the consequences of the ISB experiences ranged from feeling mild anxiety to resigning from the job. ISB was experienced in a number of work settings including schools, hospitals, private practices and universities. In general, the respondents adopted the most nonconfrontational and least assertive strategies to manage their experiences of ISB. Most of the time, the respondents did not perceive ISB to be of a harassing nature, even those experiences that resulted in significant consequences. 
The experience of ISB is an infringement of human rights, no matter if the recipient perceives the ISB not to be harassing. More than half of the respondents in the current study reported that they had experienced ISB, and although most of them did not label the experiences as harassment, they reported a range of consequences which could be classified as hostile environment harassment and to a lesser extent, quid pro quo harassment. If the experience of ISB is acknowledged to be a professional issue, then it warrants a number of questions to be researched and debated. SLP/As need to examine the implications of the high incidence of ISB, the perceptions of acceptability of ISB, and the management strategies that are used. For example, Rothstein (1993) asked whether professionals are in fact doing their clients an injustice by allowing their clients to behave inappropriately. Rothstein's question is just one of the questions that challenge professional mores in SLP/A. This is not a case of apportioning blame because ISB is an extremely complex phenomenon, but could rather be viewed as responsible appraisal of the values and the nature of the healthcare professions and its professionals to determine whether existing practices either encourage or do little to discourage ISB. The professionals might question whether they communicate effectively and explicitly to their clients and their caregivers as well as colleagues apropos the boundaries that they wish to maintain. The professions might need to determine whether clinical interventions recognise and manage adequately transference and countertransference, and furthermore, whether ISB is promoted by professional behaviours that are considered by healthcare professionals to be appropriate and integral to optimal programme efficacy. The professionals may investigate the personality traits of those attracted to the professions and might determine at which point these traits and/or behaviours become abused. Research might address issues surrounding intimacy in the professions. For example, SLP/As engage with emotional intimacy by virtue of their involvement with communication. In addition, SLP/As connect intimately on a physical basis such as in their management of clients in acute care settings, in areas such as dysphagia, and in various aspects of audiology where the audiologist is required to be in close physical proximity to the client. Assertiveness is one of the traits that deter harassment. SLP/As might reflect on whether they assert themselves as a profession and as professionals.

The successful management of ISB is dependent on the cooperation of stakeholders at a number of levels when considering that sexual harassment is an individual human rights issue, a professional issue, as well as a societal issue (Rothstein, 1993). The current study showed that $80 \%$ of the respondents agreed that SLP/As in South Africa should receive training in the management of ISB at the undergraduate level. The results of this study, not unlike those of William et al. (1999), suggest that, for various reasons, SLP/As who participated in this study may have allowed ISB to occur. They were not necessarily passive recipients of ISB in that many of them did take action and most of them expressed that they would recommend both under-graduate preparation for and post-graduate training in managing ISB. Furthermore, the study revealed that SLP/As did not perceive ISB in the clinical setting to be harassment although the consequences were often harmful. The results of the study highlighted that the experience of ISB by SLP/As is common in South Africa and that knowledge and skills are lacking with regard to the prevention of ISB as well as the recognition and management of ISB. Hence, the responsibility of training institutions, as well as employing bodies, is inarguable; however, individuals have to take responsibility for their own safety and well-being and have to be proactive in seeking information including their legal rights and responsibilities.
The vast literature on sexual harassment in the workplace has shown the complexity and pervasiveness of this world-wide phenomenon. Sexual harassment results from interactions between gender, race, and class on the power dynamics at the organisational, socio-cultural, interpersonal or individual levels. The current study did not collect race data and only women were surveyed. In addition, limited information was obtained with regard to the organisational structure of the work settings, the sociocultural status of the respondents, and their location in organisational hierarchies. However, the results of this study showed clearly the high frequency of ISB experiences by SLP/As in South Africa which calls for further research. It is recommended that further studies investigate ISB experiences within a broader framework taking cognisance particularly of the convolutions of South African history in which discrimination and power laid the foundations for current socially constructed systems. As in other geo-political contexts, social interactions, including ISB, have been carefully bred within race-gender constructions in South Africa. Future research which will inform professionals with regard to the prevention, recognition and management of ISB might address how the socially constructed systems within which SLP/As function are organized around characteristics such as race, gender, class, ethnicity, and sexuality, and how these identity systems interact and mutually shape and reinforce each other. In addition, research might examine the nature of power in the workplace of the SLP/A and its role in maintaining structures of inequality that affect individual and group identities and experiences.

As professions develop and change, so they need to examine their professional and ethical foundations. The study revealed that ISB is a common experience of SLP/As in South Africa. It is therefore incumbent on educational institutions, professional bodies, and individuals to recognise that the experience of ISB is a significant issue in professional practice in South Africa, and to put into place mechanisms for research and analysis, reflections on professional practice, and advocacy and protection of SLP/As in the workplace.

\section{REFERENCES}

Babbie, E. (1995). Practice of social research $\left(6^{\text {th }}\right.$ ed.). Belmont: Wadsworth Company.

Bezeau, S.C., Bogod, N.M., \& Mateer, C.A. (2004). Sexually intrusive behaviour following brain injury: approaches to assessment and rehabilitation. Brain Injury, I8(3), 299-313.

Broedel-Zaugg, K., Shaffer, V., Mawer, M., \& Sullivan, D.L. (1999). Frequency and severity of sexual harassment in pharmacy practice in Ohio. Journal of the American Pharmaceutical Association, 39, 677-82.

Commonwealth Sexual Discrimination Act, (1984), division 3 of part II of the Sex Discrimination Act. Retrieved on $17^{\text {th }}$ August 2006 from http://www.austlii.edu.au/au/legis/cth/consol_act/ sda1984209/

Department of Labour (1995). Labour relations act 1995, Sexual Harassment notice 1367 of 1998; Notice of code of good practice on the handling of sexual harassment cases; section 203 (2) National Economic Development and Labour council. Retrieved on $16^{\text {th }}$ August 2006 from www.saweb.co.za/labour/sexual $/ \mathrm{html}$.

Ferns, T. (2006). Under-reporting of violent incidents against nursing staff. Nursing Standard, 20 (40), 41-45.

Fitzgerald, L.F. (1993). Sexual harassment: violence against women in the workplace. American Psychologist, 48, 1070-1076. 
Goldberg, S.A. (1997). Clinical skills for speech-language pathologists. London: Singular.

Gutek, B.A. (1985). Sex and the workplace. London: Jossey-Bass Publishers.

Gutek, B.A., \& Koss, M.P. (1993). Effects of sexual harassment on women and organizations. Occupational Medicine, 8, 807-19.

Hall, K.H. (2001). Sexualization of the doctor-patient relationship: is it ever ethically permissible? Family Practice, 18(5), 511-515.

Henderson, A.D. (2003). Nurses and workplace violence: nurses' experiences of verbal and physical abuse at work. Canadian Journal of Nursing Leadership, 16(4), 82-98.

Kamel, H.K., \& Hajjar, R.R. (2004). Sexuality in the nursing home, part 2: managing abnormal behaviour - legal and ethical issues. Journal of the American Directory Association, 5(2 Supplement), S48-52.

Lawrie, B., \& Jillings, C. (2004). Assessing and addressing inappropriate sexual behavior in brain-injured clients. Rehabilitation Nursing, 29 (1), 9-13.

Madison J., \& Minichiello V. (2001). Sexual harassment in healthcare: classification of harassers and rationalizations of sex-based harassment behavior. Journal of Nursing Administration, 3l(11), 534-43.

McComas, J., Herbert, C., Giacomin, C., Kaplan, D., \& Dulberg, C. (1993). Experiences of student and practising physical therapists with inappropriate patient sexual behaviour. Physical Therapy, 73, 762-770.

Murphy, G.H. (2003). Capacity to consent to sexual relationships in adults with learning disabilities. Journal of Family Planning and Reproductive Health Care, 29(3), 148-149.

O' Sullivan, V., \& Weerakoon, P. (1999). Inappropriate sexual behaviour of patients towards practising physiotherapists: a study using qualitative methods. Physiotherapy Research International, 4(1), 28-42.

Philips, S.P., \& Schneider, M.S. (1993). Sexual harassment of female doctors by patients. New England Journal of Medicine, 329, 19361939.
Pidgeon, N., \& Henwood, K. (1996). Grounded theory: Practical implementation. In J.T.E. Richardson (Ed.), Qualitative research methods for psychology and the social sciences (pp. 86-101). London: Blackwell Publishing.

Recupero, P.R., Heru, A.M., Price, M., \& Alves, J. (2004). Sexual harassment in medical education: liability and protection. Academic Medicine, 79(9), 817-824.

Rothstein, J.M. (1993). Inappropriate patient sexual behaviors. (Editorial). Physical Therapy, 73(11), 738.

Sandberg, D. A., McNiel, D. E., \& Binder, R. I. (2002). Stalking, threatening, and harassing behavior by psychiatric patients toward clinicians. Journal of the American Academy of Psychiatry Law, 30, 221-229

Schneider, K.T., Swann, S., \& Fitzgerald, L.F. (1997). Job-related and psychological effects of sexual harassment in the workplace: empirical evidence from two organizations. Journal of Applied Psychology, 82, 401-415.

Tang, C.S., Yik, M.S., Cheung, F.M., Choi, P.K., \& Au, K.C. (1996). Sexual harassment of Chinese college students. Archives of Sexual Behaviour, 25, 201-15.

United States Equal Employment Opportunity Commission (1980). Civil Rights Act of 1964 . Retrieved on $16^{\text {th }}$ August 2006 from www. eeoc.gov.types/sexual harassment.html

Vetten, D. (2001). Race, gender and power in the face of social change. In J. Park, J. Fedler, \& Z. Dangor, (Eds.), Reclaiming Women's Spaces (pp. 47-80). Johannesburg: Nisaa Institute for Women's Development

Vukovich, M.C. (1996). The prevalence of sexual harassment among female family practice residents in the United States. Violence Victims, $11,175-80$.

Williams, T.H., de Seriere, J., \& Boddington, L. (1999). Inappropriate sexual behaviour experienced by speech-language therapists. International Journal of Language and Communication Disorders, $34,99-111$. 


\section{APPENDIX}

\section{Questionnaire: The experience of inappropriate sexual behaviour in the workplace}

(Adapted from McComas et al., 1993 and Williams et al., 1999)

\section{Demographic information}

Gender

Age

Years that you have been practicing as a SLP/A

For students, year of study

Place where you work (hospital, university, private practice, other: please specify)

Please indicate by means of an asterisk * if you feel that this behaviour is a symptom of the client's condition (e.g. brain injury, mental illness etc.) iour been experi-

Have suggestive stories ever been told to you?

Has an offensive joke ever been told to you?

Have flattering remarks about your appearance that made you uncomfortable been made?

Have you been stared at in a way that made you uncomfortable?

Have you ever been asked for a date?

Has anyone ever suggested that you 'get together' for a drink?

Have crude remarks been made to you?

Have any attempts been made to draw you into a discussion about your private sexual matters?

Have you ever been propositioned (e.g. asked you to have sex with him or her)?

Have you ever been deliberately touched (e.g. laid a hand on your bare arm or put an arm around your shoulders) in a way that made you feel uncomfortable?

Have you had genitals exposed to you?

Have you had breasts exposed to you?

Has anyone attempted to fondle you (e.g. stroked your leg or neck, or touched your breasts)?

Has anyone ever made forceful attempts to fondle you?

Has anyone ever made forceful attempts to kiss you?

Has anyone ever made forceful attempts to grab you?

Has anyone ever made attempts to have sexual intercourse with you?

Has anyone ever used force to have intercourse with you?
Has this behavenced by you? (Please circle)

Do you feel that this behaviour is harassment? (Please circle)

YES/NO $\quad$ YES/NO

YES/NO $\quad$ YES/NO

YES/NO

YES/NO

YES/NO YES/NO

YES/NO

YES/NO YES/NO

YES/NO YES/NO

YES/NO

YES/NO

YES/NO

YES/NO

YES/NO

YES/NO

YES/NO

YES/NO

YES/NO

YES/NO

YES/NO

YES/NO

YES/NO

YES/NO

YES/NO

YESS/NO

YES/NO

YES/NO

YES/NO

YES/NO

From which individuals have you experienced inappropriate sexual behaviour? (Please tick)

\begin{tabular}{|l|l|l}
\hline Client & Client's caregiver & Client's spouse \\
\hline Client's parent & Boss or employer & Other (please specify) \\
\hline
\end{tabular}

In which work contexts have you experienced inappropriate sexual behaviour? (Please tick)

School

Private practice University Hospital Other (please specify) 
Please describe the effects that the experience of inappropriate sexual behaviour had on you. Did it affect your work performance, decrease your work productivity, motivation , time off, requests to change work placement etc.?

Did it increase your physical stress (e.g. insomnia, headaches, weight gain, fatigue, pains and digestive problems)?

Did it increase your emotional stress (e.g. guilt, depression, nervousness)?

Other effects?

Please describe how you responded to the inappropriate sexual behaviour (please tick).

Did you:

Ignore the behaviour

Tell your supervisor

Discuss it with your client

Provide an ultimatum

Other (please specify)

Do you feel that you handled the situation effectively?

Do you feel that you were adequately trained during your undergraduate degree on how to handle such behaviours?

Do you feel that it would benefit future therapists if training was provided by the university at the undergraduate level?

If só, what topics do you feel should be discussed?

Do you know the South African laws regarding inappropriate sexual behaviour?

Please try to estimate how many experiences of inappropriate sexual behaviours you have had in your professional life

Please provide any comments

Thank you for participating in the study. Your involvement is appreciated. 
